\title{
Sustained Conditioned Responses in Prelimbic Prefrontal Neurons Are Correlated with Fear Expression and Extinction Failure
}

\author{
Anthony Burgos-Robles, ${ }^{\star}$ Ivan Vidal-Gonzalez, ${ }^{\star \dagger}$ and Gregory J. Quirk \\ Departments of Psychiatry and Anatomy and Neurobiology, University of Puerto Rico School of Medicine, San Juan, Puerto Rico 00936-5067
}

\begin{abstract}
During auditory fear conditioning, it is well established that lateral amygdala (LA) neurons potentiate their response to the tone conditioned stimulus, and that this potentiation is required for conditioned fear behavior. Conditioned tone responses in LA, however, last only a few hundred milliseconds and cannot be responsible for sustained fear responses to a tone lasting tens of seconds. Recent evidence from inactivation and stimulation studies suggests that the prelimbic (PL) prefrontal cortex is necessary for expression of learned fears, but the timing of PL tone responses and correlations with fear behavior have not been studied. Using multichannel unit recording techniques in behaving rats, we observed sustained conditioned tone responses in PL that were correlated with freezing behavior on a second-to-second basis during the presentation of a $30 \mathrm{~s}$ tone. PL tone responses were also correlated with conditioned freezing across different experimental phases (habituation, conditioning, extinction). Moreover, the persistence of PL responses after extinction training was associated with failure to express extinction memory. Together with previous inactivation findings, the present results suggest that PL transforms transient amygdala inputs to a sustained output that drives conditioned fear responses and gates the expression of extinction. Given the relatively long latency of conditioned responses we observed in PL ( $\sim 100 \mathrm{~ms}$ after tone onset), we propose that PL integrates inputs from the amygdala, hippocampus, and other cortical sources to regulate the expression of fear memories.
\end{abstract}

\section{Introduction}

Learning to predict danger in the environment is vital for survival. The brain is equipped with neural circuits that detect the coincidence of cues [e.g., tone conditioned stimulus (CS)] with dangerous outcomes (e.g., electrical shock). Three decades of research have established that potentiation of CS inputs within the amygdala is critical for learning these stimulus-danger associations, and that amygdala activity is required for subsequent expression of fear memory (LeDoux, 2000; Davis and Whalen, 2001; Maren and Quirk, 2004; Paré et al., 2004). Strong support for the amygdala hypothesis is derived from unit recording studies showing that neurons in the lateral nucleus of the amygdala (LA) elicit potentiated tone responses that correlate with the ac-

\footnotetext{
Received Jan. 23, 2009; revised May 21, 2009; accepted May 22, 2009.

This study was supported by National Institutes of Health Grants MH058883, MH081975, and RR03051. A.B.-R. was supported by a National Institute of Mental Health Supplement for Underrepresented Minorities, and I.G.-V. was supported by the American Psychological Association Diversity Program in Neuroscience (MH018882). This study represents part of the doctoral thesis of I.V.-G. Ivan's passion for neuroscience, and for helping others, is an example to us all. We thank Kevin A. Corcoran, Francisco Sotres-Bayon, Ki A. Goosens, and Mohammed R. Milad for providing comments on this manuscript.

${ }^{*}$ A.B.-R. and I.G.-V. contributed equally to this work.

${ }^{\dagger}$ Deceased, Aug. 25, 2006.

Correspondence should be addressed to Dr. Gregory J. Quirk, Department of Psychiatry, University of Puerto Rico School of Medicine, P.0. Box 365067, San Juan, Puerto Rico 00936-5067. E-mail: gjquirk@yahoo.com.

A. Burgos-Robles's present address: Department of Brain and Cognitive Sciences, McGovern Institute for Brain Research, Massachusetts Institute of Technology, 46-2135, 77 Massachusetts Avenue, Cambridge, MA 02139. Email: aburgos@mit.edu.

DOI:10.1523/JNEUROSCI.0378-09.2009

Copyright $\odot 2009$ Society for Neuroscience $\quad$ 0270-6474/09/298474-09\$15.00/0
}

quisition and extinction of conditioned fear (Quirk et al., 1995; Paré and Collins, 2000; Repa et al., 2001).

Although conditioned responses in LA may be responsible for triggering fear to the CS, there is a mismatch between the duration of CS-elicited activity in LA, and CS-elicited fear responses. A commonly used measure of conditioned fear in rodents is freezing, which is a sustained response that can outlast the CS presentation. Conditioned tone responses in LA are very short, only lasting a few hundred milliseconds (Quirk et al., 1995; Paré and Collins, 2000; Goosens and Maren, 2004), and, therefore, cannot be responsible for maintaining freezing responses. This suggests that there are additional structures downstream from LA that show sustained conditioned responses and are responsible for sustaining freezing. To date, however, no such structures have been described, leaving in doubt the physiological mechanisms by which CSs generate freezing responses.

One candidate structure for generating sustained conditioned fear is the prelimbic $(\mathrm{PL})$ subregion of the medial prefrontal cortex (mPFC). PL receives sensory inputs from the lateral and basal subregions of the amygdala (McDonald, 1991; Laviolette et al., 2005; Herry et al., 2008), as well as from the hippocampus and other cortical sources involved in fear conditioning (Maren et al., 1997; Thierry et al., 2000). Furthermore, PL projects back to and drives neurons in the basal amygdala (BA) (Mcdonald et al., 1996; Vertes, 2004; Likhtik et al., 2005), which is necessary for fear expression (Anglada-Figueroa and Quirk, 2005). Pharmacological inactivation of PL abolishes expression of conditioned fear (Blum et al., 2006; Corcoran and Quirk, 2007), and microstimulation of PL augments conditioned fear (Vidal-Gonzalez et al., 

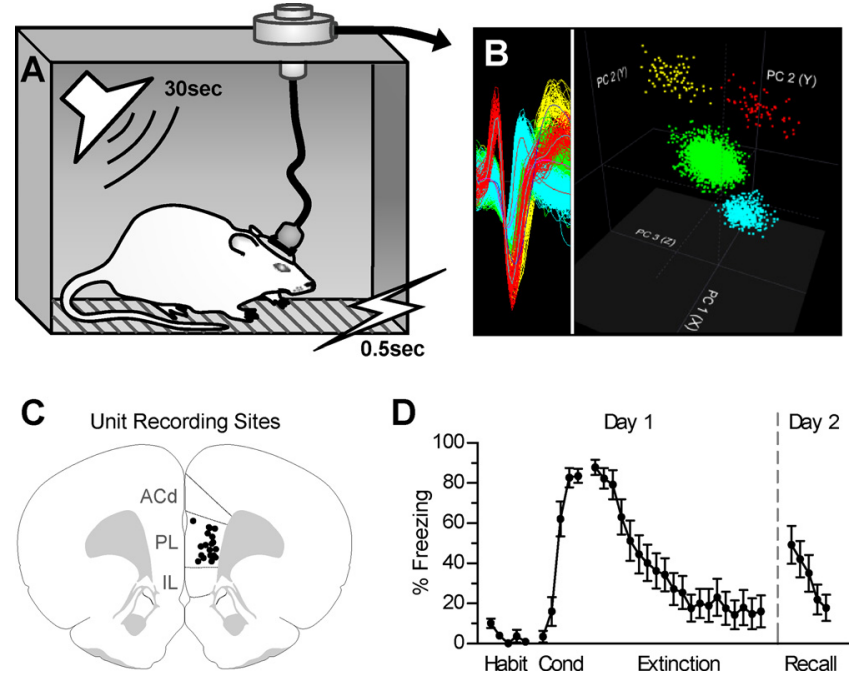

Figure 1. Multichannel unit recordings were performed in the prelimbic subregion of the medial prefrontal cortex of rats undergoing auditory fear conditioning and extinction. $A$, Rats were fear conditioned with tones of $30 \mathrm{~s}$ in length that coterminated with brief footshocks. Extinction training was conducted $2 \mathrm{~h}$ after conditioning, and the recall test occurred $24 \mathrm{~h}$ after extinction. $\boldsymbol{B}$, Representative extracellular waveform sorting. The image shows superimposed waveforms of four simultaneously recorded neurons and the clusters they formed in three-dimensional space after applying principal component analysis. C, Coronal drawing shows location of recording electrodes [bregma $+2.80 \mathrm{~mm}$; adapted from Swanson (1992); ACd, dorsal anterior cingulate]. $\boldsymbol{D}$, Percentage freezing to the tone ( $n=17)$. Significant acquisition and extinction were observed on day 1 , and substantial recall of extinction was observed on day 2 . In this and subsequent figures, error bars illustrate SEM; Habit indicates habituation, and Cond indicates conditioning.

2006). Thus, PL activity seems to be critical for fear expression, but the hypothesis that the time course of PL activity parallels the time course of conditioned fear remains untested.

Another important question is whether PL activity influences extinction of fear. Substantial evidence indicates that activity in the adjacent infralimbic (IL) $\mathrm{mPFC}$ facilitates recall of extinction (for review, see Quirk et al., 2006; Quirk and Mueller, 2008). Failure to recall extinction results from deficient IL activity (Herry and Garcia, 2002; Milad and Quirk, 2002; Barrett et al., 2003; Burgos-Robles et al., 2007), but it may also result from excessive activity in PL. To address these questions, we compared the activity profile of PL neurons with freezing behavior on a second-to-second time scale, during auditory fear conditioning and extinction.

\section{Materials and Methods}

Subjects. Male Sprague Dawley rats were individually housed and handled as described previously (Quirk et al., 2000). Food was restricted to $18 \mathrm{~g} / \mathrm{d}$ of standard laboratory rat chow until rats reached $85 \%$ of their free-feeding weight. Rats were then trained to press a bar for food on a variable interval schedule of reinforcement of $60 \mathrm{~s}$ (VI-60), to maintain constant levels of activity against which freezing can be reliably measured (Quirk et al., 2000). Food was available throughout all phases of the experiment. All procedures were approved by the local Institutional Animal Care and Use Committee in compliance with the National Institutes of Health Guidelines for the care and Use of Laboratory Animals (publication number DHHS NIH 86-23).

Surgeries and recording electrodes. Using surgical procedures explained previously (Burgos-Robles et al., 2007), rats were implanted in the PL subregion of the medial prefrontal cortex with movable arrays of microwires (16 wires of $22 \mu \mathrm{m}$ in diameter; Stablohm 650; California Fine Wire). Before electrodes were implanted, the tip of each wire was plated with gold by passing a cathodal current of $1 \mu \mathrm{A}$ while cables were submerged in a gold solution. This procedure was performed to reduce impedance to a range of $250-350 \mathrm{k} \Omega$. Electrodes were implanted in stereotaxic coordinates $2.9 \mathrm{~mm}$ anterior, $0.5-0.8 \mathrm{~mm}$ lateral, and $4.0 \mathrm{~mm}$ ventral from bregma. Rats were allowed 5-7 d to recover from surgery. Rats were then acclimated to recording procedures while electrodes were driven in steps of $44 \mu \mathrm{m}$ to isolate extracellular waveforms.

Fear conditioning and extinction. Rats were fear conditioned and extinguished in standard operant chambers (Coulbourn Instruments) located inside sound-attenuating boxes (MED Associates) in an isolated testing room. Details of the apparatus have been described in our previous studies (Quirk et al., 2000). Rats received five habituation trials (sine wave tones at $4 \mathrm{kHz}$, $75 \mathrm{~dB}, 30 \mathrm{~s}$ ) immediately followed by fear conditioning consisting of five tone presentations that coterminated with mild footshocks $(0.4$ $\mathrm{mA}, 0.5 \mathrm{~s})$. At the end of the conditioning phase, rats were transported to their homecages, and $2 \mathrm{~h}$ later they were brought back to the same operant chamber to receive extinction training, consisting of 20 tone-alone trials. Twenty-four hours later, rats were returned to the chambers to test for recall of extinction with additional tone-alone trials. The interval between successive tones was variable with an average of $2.5 \mathrm{~min}$.

The behavior of rats was monitored with digital video cameras (Micro Video Products) and analyzed from video tapes. Freezing, defined as the absence of all movements except those related to breathing (Blanchard and Blanchard, 1972), served as the measurement of fear. An experimenter blinded with respect to experimental phase quantified the total time that rats spent freezing during the $30 \mathrm{~s}$ tone presentations, using a digital stopwatch. For a finer temporal resolution, freezing was also scored in a second-to-second time scale. Freezing data were plotted in single trials, and comparisons across experimental phases were made using repeated-measures ANOVA with post hoc Tukey Honestly Significant Difference tests (Statistica; StatSoft).

Multichannel unit recordings and unit analyses. Extracellular waveforms exceeding a voltage threshold were digitized at $40 \mathrm{kHz}$ and stored on a personal computer. Waveforms were recorded during pretone, tone, and post-tone periods, each lasting 30 s. Shock artifacts during the conditioning phase were prevented from entering the recording files by turning off recording during shock delivery. Waveforms were then sorted off-line using three-dimensional plots of principal component and voltage vectors (Offline Sorter; Plexon). Clusters formed by individual neurons were tracked across conditioning, extinction, and recall phases by applying cluster boundaries and manually checking for goodness of fit. Timestamps of neural spiking and flags for the occurrence of tones and shocks were imported to NeuroExplorer for analysis (NEX Technologies).

A total of 81 PL neurons from 17 rats were maintained throughout habituation, conditioning, and extinction phases on day 1 . Of these 81, 51 neurons from 15 rats were maintained during the recall phase on day 2. PL activity was examined across seconds to evaluate tone-induced changes in activity and across experimental phases to evaluate traininginduced changes in activity. Two trials per phase were averaged and examined for the detection of tone responses: trials $4-5$ in habituation, trials $4-5$ in conditioning, trials $1-2$ in extinction training ("early extinction"), trials 19-20 in extinction ("late extinction"), and trials $1-2$ at extinction recall.

To detect tone-elicited changes in PL activity, we divided the 30 s tone into 10 bins, each $3 \mathrm{~s}$ in duration. A $z$-score for each of these bins was calculated, relative to 10 pretone bins of equal duration. PL neurons were classified as showing excitatory tone responses if any two tone bins exceeded $2.58 z$ 's ( $p<0.01$, two-tails). The same criterion was used to detect inhibitory tone responses $\left(z^{\prime} \mathrm{s}<-2.58\right)$. A chi-square $\left(\chi^{2}\right)$ test was used to detect differences in the proportion of tone-responsive neurons across phases. Furthermore, group perievent time histograms were gen- 
A

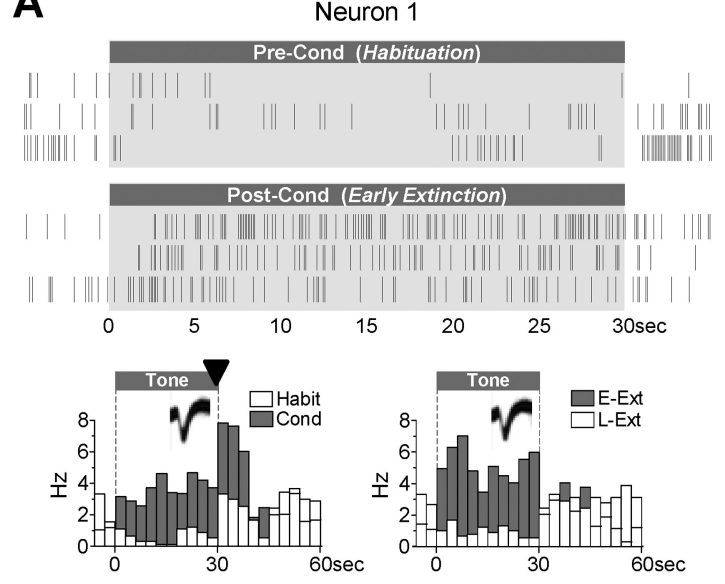

B

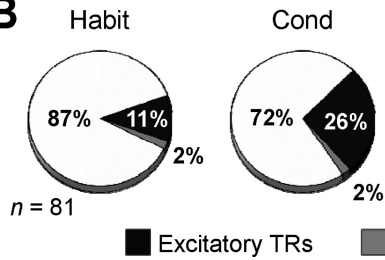

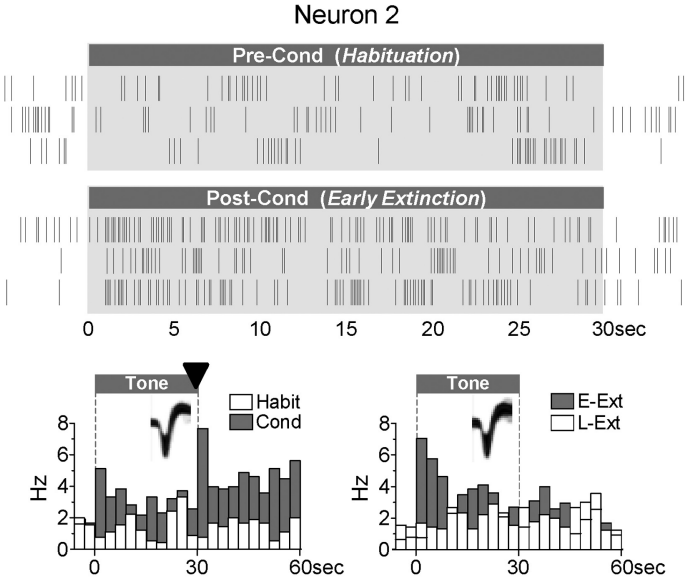
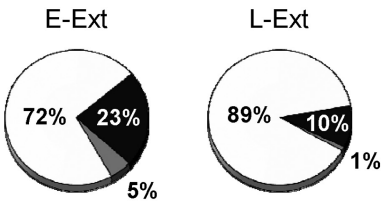

Figure 2. Prelimbic neurons showed sustained excitatory responses to conditioned tones. $\boldsymbol{A}$, Spike trains of two representative neurons before conditioning and after fear conditioning. Perievent time histograms show the response of these two neurons to tones across different phases of the experiment (bin width, $3 \mathrm{~s}$ ). These neurons responded to tones in a sustained manner during high-fear states (conditioning and early extinction) and stopped responding to tones by the end of the extinction session (late extinction). These neurons also responded to footshocks ( $\boldsymbol{\nabla}$ ) during the conditioning phase. $\boldsymbol{B}$, Pie charts illustrate the percentage of PL neurons showing excitatory or inhibitory tone responses (TRs; see Materials and Methods for criteria used to detect tone responses). The proportion of neurons showing excitatory tone responses significantly increased from habituation to conditioning and decreased from early extinction to late extinction ( $\chi^{2}$ test, $p^{\prime} s<0.05$ ). A small proportion of neurons showed inhibitory tone responses, which did not change significantly with conditioning or extinction training ( $p$ 's $>0.27$ ). In this and subsequent figures, E-Ext indicates early extinction, and L-Ext indicates late extinction.

erated by averaging $z$-scores of all tone-responsive neurons, and comparisons across experimental phases were made using repeated-measures ANOVA. Pearson's correlational test was used to compare PL activity and freezing responses across seconds, in which each point in the correlation was composed by the average PL activity and the average freezing for a given $3 \mathrm{~s}$ bin (22 bins in total: 2 pretone bins, 10 tone bins, and 10 post-tone bins).

Burst firing was also examined by measuring the percentage of spikes within bursts. As in our previous study (Burgos-Robles et al., 2007), a burst was defined as three or more consecutive spikes with an interspike interval of $<25 \mathrm{~ms}$ between the first two spikes and $<50 \mathrm{~ms}$ for subsequent spikes. This criterion is consistent with previously reported firing properties of prefrontal neurons (Shi and Zhang, 2003; Laviolette et al., 2005). ANOVA was used to detect significant training-induced changes in bursting.

Spike synchrony was also assessed, by computing cross-correlations between simultaneously recorded neurons. Cross-correlations were examined for 255 cell pairs, from which 108 were excluded because of low firing rates $(0.5 \mathrm{~Hz})$ by reference cells. Correlograms were generated in 10 ms bins; they were smoothed using Gaussian filter with filter-width of three bins, and 5 trials were considered in each training phase. Furthermore, shift-predictor correlograms were generated by averaging over all possible trial shuffles, and they were subtracted from the raw correlograms. Significant peaks were detected within $100 \mathrm{~ms}$ of the reference spikes using paired $t$ tests (significance level, $p<0.001$ ) that compared 20 bins around reference spikes (from -100 to $100 \mathrm{~ms}$ in the correlograms) with 20 baseline bins (from -500 to $-300 \mathrm{~ms}$ ). Training-induced changes in spike synchrony were detected by comparing across phases the average firing rate around reference spikes using paired $t$ test.

Histology. At the conclusion of experiments, a marking lesion was produced at the tip of the recording wires by passing an anodal current of $25 \mu \mathrm{A}$ for $18 \mathrm{~s}$. Rats were perfused with $10 \%$ buffered formalin, brains were removed, and microlesions were marked with a green reaction $(6 \%$ ferrocyanide) while fixing the tissue in a $30 \%$ sucrose-10\% buffered formalin solution. Location of marking lesions was reconstructed onto atlas coronal templates adapted from Swanson (1992) from $40 \mu \mathrm{m}$ Nisslstained brain sections.

\section{Results}

Multichannel unit recordings were performed on rats undergoing auditory fear conditioning and extinction (Fig. 1). Freezing behavior served as a measure of fear. As shown in Figure $1 D$, rats acquired significant levels of freezing to the tone as conditioning proceeded (repeated-measures ANOVA, $F_{(4,64)}=59.2 ; p<$ $0.001)$ and diminished freezing with extinction training $\left(F_{(19,304)}\right.$ $=23.5 ; p<0.001)$. Rats showed substantial recall of extinction $24 \mathrm{~h}$ later (freezing levels at the beginning of extinction vs at the beginning of recall, $\left.F_{(1,16)}=23.9 ; p<0.001\right)$.

\section{Fear conditioning induces sustained conditioned unit responses in a subpopulation of prelimbic neurons}

Tone responses were examined for 81 PL neurons recorded from 17 rats that were maintained throughout habituation, conditioning, and extinction training. Fear conditioning dramatically increased the spiking rate of a number of PL neurons, throughout the presentation of tones. These sustained excitatory responses can be observed in Figure 2A, which shows spike trains of two representative neurons before fear conditioning (during habituation trials) and after fear conditioning (during early extinction trials). Perievent time histograms for these neurons revealed that tone-elicited responses were present during high-fear states (conditioning and early extinction) but not during low-fear states (habituation and late extinction). 

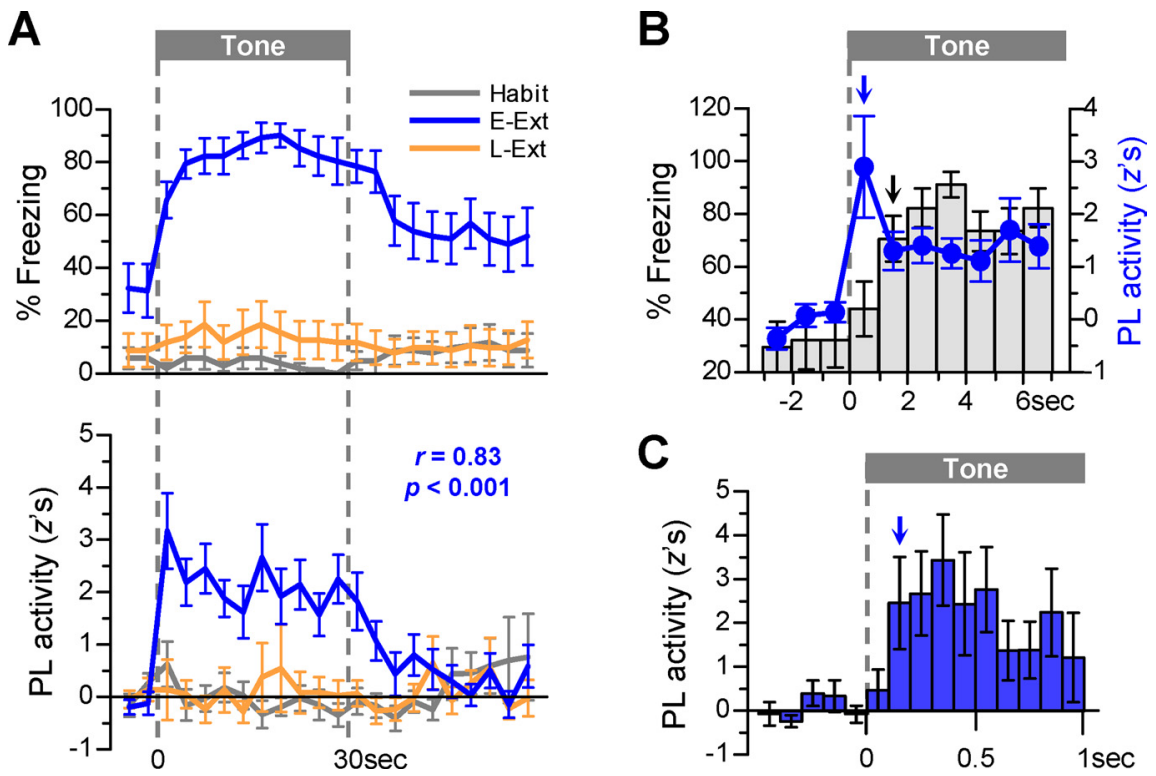

Figure 3. Conditioned responses in prelimbic neurons were highly correlated with the time course of conditioned freezing. $A$, Top, Freezing was assessed on a second-to-second time scale and plotted in $3 \mathrm{~s}$ bins. $A$, Bottom, Average tone response of neurons classified as tone responsive in early extinction $(n=19$ of $81,23 \%$ ). Neuronal activity resembled freezing in all phases, especially during early extinction in which there was a significant correlation between the two measures across bins $(r=0.83)$. $\boldsymbol{B}$, Response latency of PL activity (blue line plot) and freezing (bars) during early extinction (1 s bins are plotted). Significant tone responses in PL were evident from the very first second after tone onset, whereas significant freezing was not observed until after two seconds ( $\downarrow p<0.001$, compared with pretone). C, Earliest tone response latency in PL. Short-latency responses were examined in the 15 neurons showing significant $z$-scores in the first $3 \mathrm{~s}$ bin in $A$. These neurons did not start signaling the tone until $100 \mathrm{~ms}$ after tone onset ( $\downarrow p<0.05$, compared with pretone).

The percentage of neurons showing excitatory tone responses $(z>2.58$ in two or more tone bins) was calculated at different time points of the experiment. As illustrated in Figure $2 B$, fear conditioning increased the percentage of neurons showing excitatory responses from $11 \%$ to $26 \%$ (black-filled area in pie charts; $\chi^{2}=4.98, p=0.026$ ). This conditioning effect was reversed by extinction training, which reduced the percentage of responsive neurons from 23 to $10 \%\left(\chi^{2}=4.95, p=0.026\right)$. Only a small proportion of neurons showed inhibitory tone responses (grayfilled area in pie charts), which did not change significantly with conditioning or extinction ( $p$ 's $>0.27$ ).

The time course of conditioned responses in the prelimbic cortex is highly correlated with expression of freezing Combined with previous inactivation studies, the sustained nature of PL conditioned responses suggests that they contribute to the generation of sustained freezing responses. To examine this hypothesis, we compared the activity of PL neurons showing significant excitatory tone responses with freezing on a second-to-second timescale. We observed that conditioned responses in PL were correlated with the time course of freezing. The top panel on Figure $3 A$ shows the time course of freezing before conditioning (habituation), after conditioning (early extinction), and after extinction (late extinction). Second-to-second freezing significantly differed among the training phases, according to repeated-measures ANOVA (main effect of training phase, $F_{(2,48)}=35.2$, $p<0.001$; seconds, $F_{(21,1008)}=8.48, p<0.001 ;$ phase vs seconds interaction, $\left.F_{(42,1008)}=8.23, p<0.001\right)$. PL activity tended to parallel freezing responses in all phases. The bottom panel in Figure $3 \mathrm{~A}$ illustrates the average activity of those PL neurons showing excitatory tone responses during early extinction (19 of 81 neurons, 23\%). Similar to freezing during early extinction, the activity of these neurons significantly increased at tone onset, remained high throughout the tone presentation, outlasted the tone, and gradually came back to pretone levels. Furthermore, as with freezing, the response of these neurons returned to habituation levels by the end of extinction training. An ANOVA comparing tone responses across phases showed significantly higher tone-elicited PL activity during early extinction (training phase: $F_{(2,54)}=13.9, p<0.001$; seconds: $F_{(21,1134)}=2.67, p<0.001$; interaction: $\left.F_{(42,1134)}=3.38, p<0.001\right)$. A bin-bybin comparison of PL activity (Fig. $3 A$, bottom) and freezing (Fig. $3 A$, top) showed that the two measures were significantly correlated during early extinction $(r=0.83$, df $=20, p<0.001)$. No significant correlations were observed during habituation $(r=0.41, p=0.06)$ and late extinction $(r=0.07, p=0.76)$.

A significant correlation between PL activity and freezing during early extinction supports the hypothesis that PL activity contributes to the generation of freezing. An alternative hypothesis is that freezing triggers PL activity. To distinguish between these two alternatives, we examined the response latency of freezing and PL activity during early extinction, in $1 \mathrm{~s}$ bins. As shown in Figure $3 B$, the onset of PL tone responses (blue line plot) preceded the onset of freezing responses (gray bar graph). Significant tone-induced increased activity in PL was evident from the very first second after tone onset, whereas significant freezing did not occur until $2 \mathrm{~s}$ after tone onset. To assess the earliest tone response latency in PL, we examined activity in $100 \mathrm{~ms}$ bins. PL tone responses were not evident until after $100 \mathrm{~ms}$ after tone onset (Fig. 3C). These findings argue against the hypothesis that PL tone responses are induced by freezing.

To further test our hypothesis that PL activity parallels freezing, we took advantage of within-subject variability to perform activity-behavior correlations for single PL neurons. For each neuron-rat pair, activity and freezing were averaged across five trials during early extinction. This analysis showed that changes in PL activity across the tone paralleled changes in freezing. As shown in Figure 4, more neurons showed positive correlations with freezing than negative correlations (66 vs 34\%; binomial probability test, $p=0.007)$. Furthermore, $24 \%$ of the activityfreezing pairs showed significant positive correlations ( $r$ 's $>0.55$, $p$ 's $<0.01$ ), whereas only $4 \%$ showed significant negative correlations ( $r$ 's $<-0.55$ ) (proportion of significant positive vs negative correlations: $\left.\chi^{2}=7.85, p=0.005\right)$. Altogether, the present findings support the hypothesis that PL activity mediates conditioned fear responses.

\section{Fear conditioning increases bursting and synchrony in prelimbic neurons}

In addition to increased rate during the tone, PL neurons showed increased bursting after conditioning. As shown in Figure 5, levels of bursting during the tone increased with conditioning and 

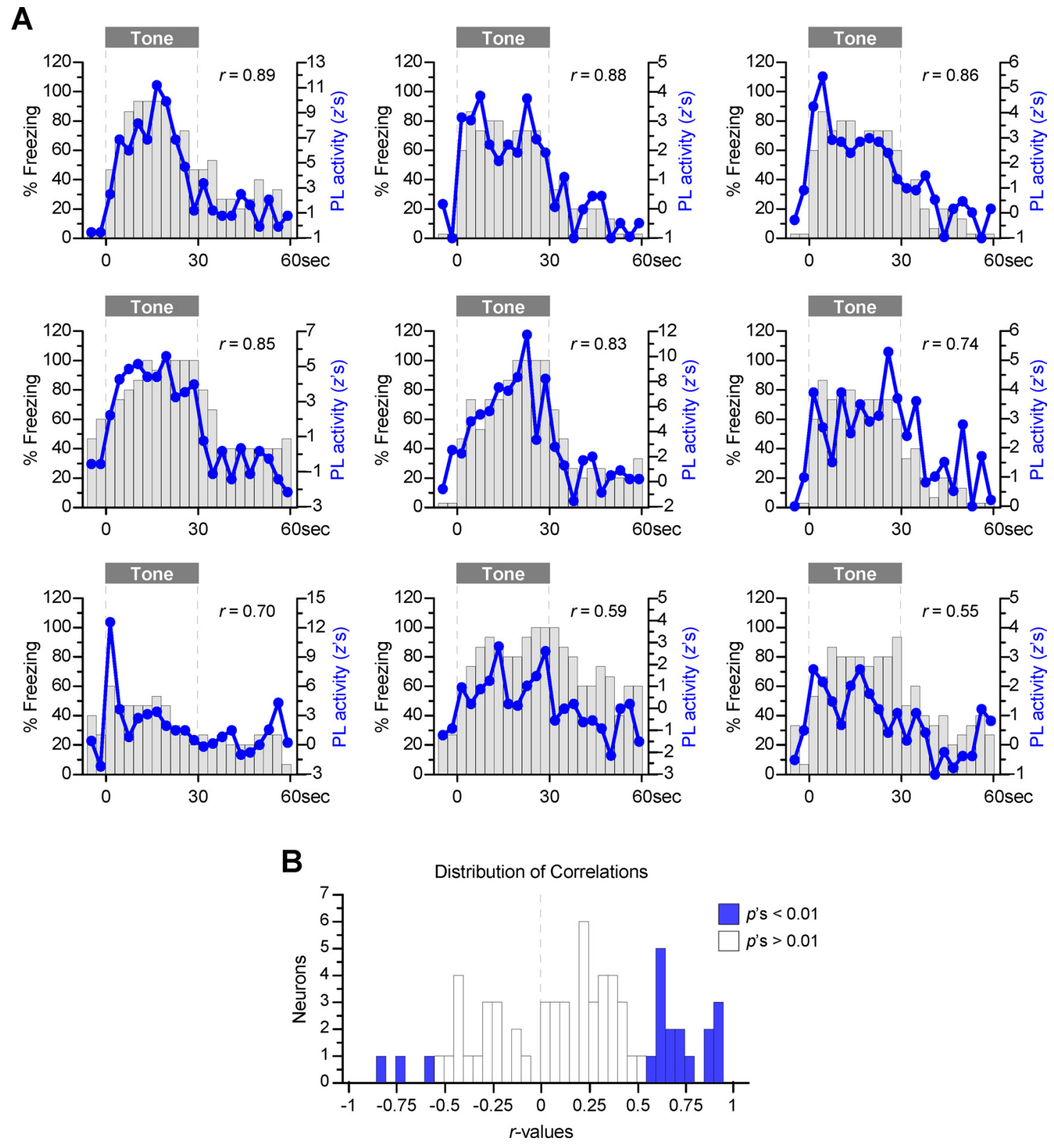

Figure 4. Single-neuron examples of prelimbic activity versus freezing. $A$, The activity of single neurons was averaged over five trials during early extinction, and the normalized tone response (line plots) was graphed on top of freezing values for a given rat (bars). Nine examples of activity-behavior correlations are shown in descending order. $\boldsymbol{B}$, Distribution of 67 correlations obtained (14 of 81 neurons were excluded from this analysis because of low firing rates, $<0.05 \mathrm{~Hz}$ ). There was a greater number of positive correlations than negative correlations ( $66 \mathrm{vs} 34 \%$; binomial proportions test, $p=0.007$ ). Furthermore, although $24 \%$ of the correlations were significantly positive ( 16 of 67 , blue bars on the right), only $4 \%$ were significantly negative ( 3 of 67 , blue bars on the left).

tended to reduce with extinction training (Fig. $5 A)\left[F_{(2,36)}=3.69\right.$, $p=0.035$; habit vs early extinction, $p=0.029$; early ext vs late ext, $p=0.19]$. Training-induced changes in bursting paralleled changes in firing rate during the tone (Fig. $5 B)\left(F_{(2,36)}=11.7, p<\right.$ 0.001 ; habit vs early ext, $p<0.001$; early ext vs late ext, $p=$ $0.0013)$, although these increases were not correlated with each other across neurons (Fig. $5 C)(r=-0.09, \mathrm{df}=17, p=0.71)$. This suggests that increased bursting was not an epiphenomenon of increased rate. In contrast to the tone, spontaneous activity during pretone periods did not differ across phases (pretone bursting: $F_{(2,36)}=0.73, p=0.49$; pretone rate: $F_{(2,36)}=1.32, p=$ $0.28)$.

Cross-correlations between simultaneously recorded neurons showed increased synchrony during tone periods as a function of conditioning. Correlograms for 36 of 147 cell pairs (24\%) showed significant peaks within $100 \mathrm{~ms}$ of reference spikes (see Materials and Methods for analysis of cross-correlations). The average correlogram for these 36 cell pairs (corrected with shift predictors) is shown in Figure 5D. Compared with the habituation phase, early extinction showed significantly more activity around reference spikes $\left(t_{(35)}=\right.$ 2.69, $p=0.011$ ), consistent with increased spike synchrony. Together with increased bursting, this suggests that conditioning increases the impact of PL on its target structures.

Failure to recall extinction is associated with increased tone responsiveness in the prelimbic cortex

Does PL activity influence recall of extinction? To address this question, we examined tone responsiveness of PL neurons $24 \mathrm{~h}$ 
A

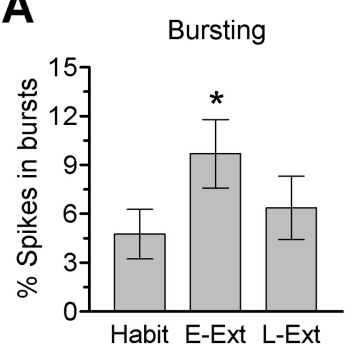

D

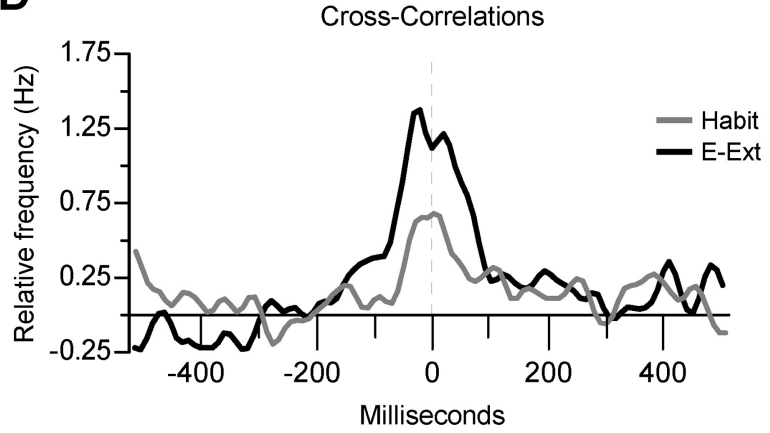

Figure 5. Conditioning increased bursting and synchrony in prelimbic neurons. $\boldsymbol{A}, \boldsymbol{B}$, Average bursting and rate during tone periods of neurons that were tone-responsive during early extinction $(n=19)$. Bursting was significantly higher during early extinction than during habituation $\left({ }^{*} p=0.03\right.$ ) and tended to reduce with extinction training ( $p=0.19$, early ext vs late ext). $\boldsymbol{B}$ These training-induced changes in bursting are similar to those observed in firing rate ${ }^{* *} p^{\prime} s<0.01$, early ext vs habit and late ext). C, Relationship between rate and bursting during early extinction. Each dot represents a single neuron, and values are expressed as changes from habituation levels. The lack of correlation $(r=-0.09)$ suggests that changes in bursting occurred independently of changes in firing rate. $\boldsymbol{D}$, Cross-correlations between simultaneously recorded cell pairs during tone periods. Histograms show the average of 36 of 147 (24\%) correlograms showing significant peaks during early extinction (see Materials and Methods for statistical analysis). The peak of the group correlogram was significantly higher during early extinction than during habituation (paired $t$ test, $p=0.011$ ). (Correlograms were smoothed using Gaussian filter, with filter width of $310 \mathrm{~ms}$ bins; $y$-axis represents relative firing frequency after subtracting shift-predictor values.)

after extinction training. Similar to our previous study (BurgosRobles et al., 2007), freezing levels at recall were bimodally distributed across rats, with a cutoff at 50\% freezing (Fig. 6 A). Of 15 rats tested, eight rats showed $<50 \%$ freezing, indicating good recall of extinction (low-fear subgroup), and seven rats showed $>50 \%$ freezing, indicating poor recall of extinction (high-fear subgroup). Repeated-measures ANOVA confirmed a main effect of subgroup at the recall phase $\left(F_{(1,13)}=37.9, p<0.001\right)$ and revealed no significant subgroup difference during conditioning $\left(F_{(1,13)}=0.47, p=0.50\right)$ and extinction training $\left(F_{(1,13)}=3.70\right.$, $p=0.077)$.

We, therefore, compared excitatory PL tone responses in these two subgroups of rats. As shown in Figure $6 B$, high-fear rats showed significantly larger PL tone responses at recall than lowfear rats $\left(t_{(16)}=2.16, p=0.046\right)$. Furthermore, high-fear rats exhibited a somewhat higher percentage of tone-responsive neurons during conditioning (32 vs $22 \%$ ), extinction training (37 vs $19 \%$ ), and recall (47 vs 28\%) (Fig. 6C). However, because of low numbers, these proportions did not reach significance. Thus, increased conditioning in PL neurons may contribute to poor recall of extinction the following day.

\section{Discussion}

We performed multichannel unit recordings in behaving rats to determine the firing profile of prelimbic neurons during auditory fear conditioning and extinction. We observed that activity of PL neurons is correlated with the expression of fear, across multiple domains: (1) PL neurons showed conditioned responses that dissipated with extinction; (2) PL conditioned responses were sustained throughout the presentation of conditioned tones, correlating with the expression of tone-induced freezing; and (3) the magnitude of tone responses in $\mathrm{PL}$ was higher in rats that failed to recall extinction. These findings suggest that PL activity is important for the expression of fear and extinction memories.

Behavioral studies support the idea that PL controls fear expression. Pharmacological inactivation of PL considerably reduced the expression of fear to conditioned tones and contexts (Blum et al., 2006; Corcoran and Quirk, 2007). Deficits in fear expression were also observed after manipulations that impaired glutamate and nitric oxide neurotransmission in PL (Resstel et al., 2008). Furthermore, electrical stimulation of PL increased expression of conditioned fear (Vidal-Gonzalez et al., 2006). Thus, these inactivation and stimulation findings suggest that PL contributes to the expression of conditioned fear, and that the amygdala, although necessary for fear expression (LeDoux, 2000; Davis and Whalen, 2001; Maren and Quirk, 2004; Paré et al., 2004), is not sufficient.

Prior studies have reported fear-related conditioned responses in PL neurons. Conditioned responses in PL have been observed in heart rate and eyeblink conditioning tasks (Maxwell et al., 1994; Powell et al., 1996; McLaughlin et al., 2002) and in delay and trace fear conditioning (Baeg et al., 2001; Gilmartin and McEchron, 2005; Laviolette et al., 2005). These authors, however, could not correlate PL responses with sustained fear behavior, because they used short-duration conditioned stimuli (e.g., $2 \mathrm{~s}$ ) or used restrained or anesthetized preparations that did not allow for the measurement of behavior. Using a long-duration stimulus (30 s) in unrestrained rats, we were able to observe sustained conditioned responses in a subset of PL neurons that correlated with sustained freezing behavior during both conditioning and extinction. This suggests that PL drives fear behavior and modulates extinction. In support of this hypothesis, recent studies examining neuronal activity with cFos showed that PL activation is correlated with fear expression (Herry and Mons, 2004; Ferreira-Netto et al., 2007; Knapska and Maren, 2008) and extinction failure (Muigg et al., 2008).

PL neurons may receive short-lasting responses from the amygdala, but how are these converted into sustained conditioned responses? In addition to inputs from the basolateral amygdala, PL receives input from the hippocampus and auditory cortex (McDonald, 1991; Thierry et al., 2000; Gabbott et al., 2006). Costimulation of the amygdala and the hippocampus produces excitatory convergence in PL neurons (Ishikawa and $\mathrm{Na}$ kamura, 2003), suggesting that PL may integrate signals from various structures to produce sustained responding. It is also likely that fear-induced release of neuromodulators such as norepinephrine and dopamine in PL (Hugues et al., 2007) increases the excitability of PL neurons, thus making PL more responsive 
to amygdala, hippocampal, and tone inputs. In support of this model, it was recently shown that the noradrenergic antagonist propranolol reduced the firing rate of PL neurons and reduced fear expression (Rodriguez-Romaguera et al., 2009) and that dopamine increased PL excitability by reducing local inhibition (Floresco and Tse, 2007). In this manner, neuromodulators could augment the impact of PL inputs to produce sustained responding. Thus, PL may act as a site of convergence that integrates auditory, contextual, and stress-related signals to calculate an appropriate behavioral response to a conditioned stimulus (Corcoran and Quirk, 2007) (Fig. 7, model).

Several lines of evidence suggest that PL drives fear expression via the BA. PL projects to, and excites, neurons in $\mathrm{BA}$ (Room et al., 1985; Mcdonald et al., 1996; Vertes, 2004; Likhtik et al., 2005), and post-training lesions of BA abolish fear expression (Anglada-Figueroa and Quirk, 2005). Thus, PL could drive BA, which in turn projects to output neurons in the central nucleus of the amygdala to produce fear responses (Kapp et al., 1979; LeDoux et al., 1988; Goosens and Maren, 2001). Complementary pathways by which PL may drive fear responses include direct projections to the ventrolateral periaqueductal gray (PAG), which mediates expression of conditioned freezing, the ventral striatum which mediates avoidance responses, and the lateral hypothalamus which mediates autonomic conditioned responses (LeDoux et al., 1988; Brog et al., 1993; De Oca et al., 1998; Amorapanth et al., 1999; Floyd et al., 2000; Schoenbaum and Setlow, 2003; Gabbott et al., 2005). One prediction from this model is that neurons in BA, PAG, striatum, and hypothalamus may show sustained conditioned responses, similar to those we observed in PL.

Interestingly, we observed that rats showing poor recall of extinction had a higher percentage of PL neurons responding to tones. This was true during the recall test, as well as shortly after conditioning, suggesting that these rats had excessive consolidation of fear memory. Extinction failure could, therefore, be caused by excessive activity in PL, combined with deficient activity in the IL PFC, a structure responsible for inhibiting fear after extinction (Herry and Garcia, 2002; Milad and Quirk, 2002; Barrett et al., 2003; Vidal-Gonzalez et al., 2006; Burgos-Robles et al., 2007). In this way, recall of fear and extinction memories may depend on the optimal balance of activity between PL and IL. This concept may be clinically relevant, as it is known that recall of extinction in humans is modulated by activity in prefrontal homologues of PL and IL, the dorsal anterior cingulate (dACC), and the ventromedial prefrontal cortex (vmPFC) (Phelps et al., 2004; Kalisch et al., 2006; Milad et al., 2007a,b). In fact, anxiety disorders are associated with decreased activity in vmPFC coupled with increased activity in dACC (Shin et al., 2006, 2007; Liberzon and Sripada, 2008; Milad et al., 2008). Thus, future therapies for anxiety disorders may be aimed at restoring the balance of activity within this prefrontal network, as recently suggested (Schienle et al., 2007; Schiepek et al., 2008).
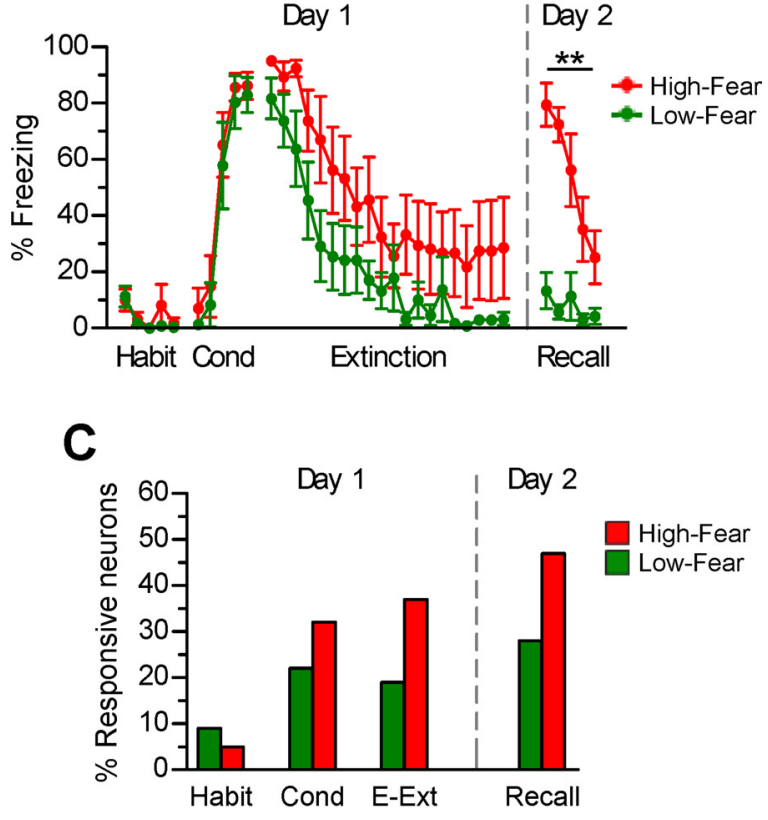

Figure 6. Failure to recall extinction was associated with increased prelimbic tone responses. $\boldsymbol{A}$, Rats were divided into two

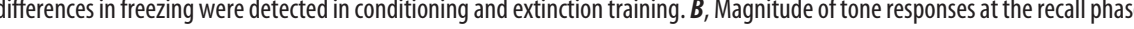
responsive neurons at recall, as well as during conditioning and early extinction.

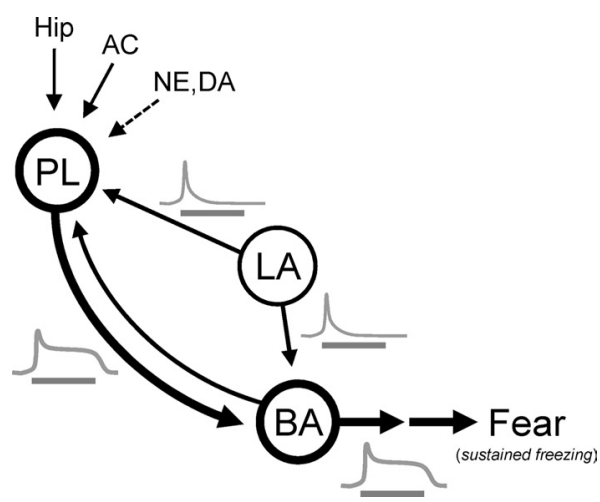

Figure 7. Suggested model by which the prelimbic cortex maintains the expression of conditioned freezing. PL receives convergent inputs from several sources: the LA and BA (providing information regarding the tone-shock association), the hippocampus (Hip) (providing contextual information), and the auditory cortex (AC) (providing auditory information). By integrating these inputs, together with fear-induced release of neuromodulators such as norepinephrine (NE) and dopamine (DA), PL could convert phasic inputs from the amygdala into sustained outputs (see traces in gray). In this scenario, thus, PL integrates auditory, contextual, and stress-related signals to calculate an appropriate behavioral response to a conditioned stimulus.

\section{References}

Amorapanth P, Nader K, LeDoux JE (1999) Lesions of periaqueductal gray dissociate-conditioned freezing from conditioned suppression behavior in rats. Learn Mem 6:491-499.

Anglada-Figueroa D, Quirk GJ (2005) Lesions of the basal amygdala block expression of conditioned fear but not extinction. J Neurosci 25:9680-9685.

Baeg EH, Kim YB, Jang J, Kim HT, Mook-Jung I, Jung MW (2001) Fast 
spiking and regular spiking neural correlates of fear conditioning in the medial prefrontal cortex of the rat. Cereb Cortex 11:441-451.

Barrett D, Shumake J, Jones D, Gonzalez-Lima F (2003) Metabolic mapping of mouse brain activity after extinction of a conditioned emotional response. J Neurosci 23:5740-5749.

Blanchard DC, Blanchard RJ (1972) Innate and conditioned reactions to threat in rats with amygdaloid lesions. J Comp Physiol Psychol 81:281-290.

Blum S, Hebert AE, Dash PK (2006) A role for the prefrontal cortex in recall of recent and remote memories. Neuroreport 17:341-344.

Brog JS, Salyapongse A, Deutch AY, Zahm DS (1993) The patterns of afferent innervation of the core and shell in the "accumbens" part of the rat ventral striatum: immunohistochemical detection of retrogradely transported fluoro-gold. J Comp Neurol 338:255-278.

Burgos-Robles A, Vidal-Gonzalez I, Santini E, Quirk GJ (2007) Consolidation of fear extinction requires NMDA receptor-dependent bursting in the ventromedial prefrontal cortex. Neuron 53:871-880.

Corcoran KA, Quirk GJ (2007) Activity in prelimbic cortex is necessary for the expression of learned, but not innate, fears. J Neurosci 27:840-844.

Davis M, Whalen PJ (2001) The amygdala: vigilance and emotion. Mol Psychiatry 6:13-34.

De Oca BM, DeCola JP, Maren S, Fanselow MS (1998) Distinct regions of the periaqueductal gray are involved in the acquisition and expression of defensive responses. J Neurosci 18:3426-3432.

Ferreira-Netto C, Borelli KG, Brandão ML (2007) Distinct Fos expression in the brain following freezing behavior elicited by stimulation with NMDA of the ventral or dorsal inferior colliculus. Exp Neurol 204:693-704.

Floresco SB, Tse MT (2007) Dopaminergic regulation of inhibitory and excitatory transmission in the basolateral amygdala-prefrontal cortical pathway. J Neurosci 27:2045-2057.

Floyd NS, Price JL, Ferry AT, Keay KA, Bandler R (2000) Orbitomedial prefrontal cortical projections to distinct longitudinal columns of the periaqueductal gray in the rat. J Comp Neurol 422:556-578.

Gabbott PL, Warner TA, Jays PR, Salway P, Busby SJ (2005) Prefrontal cortex in the rat: projections to subcortical autonomic, motor, and limbic centers. J Comp Neurol 492:145-177.

Gabbott PL, Warner TA, Busby SJ (2006) Amygdala input monosynaptically innervates parvalbumin immunoreactive local circuit neurons in rat medial prefrontal cortex. Neuroscience 139:1039-1048.

Gilmartin MR, McEchron MD (2005) Single neurons in the medial prefrontal cortex of the rat exhibit tonic and phasic coding during trace fear conditioning. Behav Neurosci 119:1496-1510.

Goosens KA, Maren S (2001) Contextual and auditory fear conditioning are mediated by the lateral, basal, and central amygdaloid nuclei in rats. Learn Mem 8:148-155.

Goosens KA, Maren S (2004) NMDA receptors are essential for the acquisition, but not expression, of conditional fear and associative spike firing in the lateral amygdala. Eur J Neurosci 20:537-548.

Herry C, Garcia R (2002) Prefrontal cortex long-term potentiation, but not long-term depression, is associated with the maintenance of extinction of learned fear in mice. J Neurosci 22:577-583.

Herry C, Mons N (2004) Resistance to extinction is associated with impaired immediate early gene induction in medial prefrontal cortex and amygdala. Eur J Neurosci 20:781-790.

Herry C, Ciocchi S, Senn V, Demmou L, Müller C, Lüthi A (2008) Switching on and off fear by distinct neuronal circuits. Nature 454:600-606.

Hugues S, Garcia R, Léna I (2007) Time course of extracellular catecholamine and glutamate levels in the rat medial prefrontal cortex during and after extinction of conditioned fear. Synapse 61:933-937.

Ishikawa A, Nakamura S (2003) Convergence and interaction of hippocampal and amygdalar projections within the prefrontal cortex in the rat. J Neurosci 23:9987-9995.

Kalisch R, Korenfeld E, Stephan KE, Weiskopf N, Seymour B, Dolan RJ (2006) Context-dependent human extinction memory is mediated by a ventromedial prefrontal and hippocampal network. J Neurosci 26:9503-9511.

Kapp BS, Frysinger RC, Gallagher M, Haselton JR (1979) Amygdala central nucleus lesions: effect on heart rate conditioning in the rabbit. Physiol Behav 23:1109-1117.

Knapska E, Maren S (2008) Reciprocal patterns of c-Fos expression in the medial prefrontal cortex and amygdala after extinction and renewal of conditioned fear in rats. Soc Neurosci Abstr 34:487.15.

Laviolette SR, Lipski WJ, Grace AA (2005) A subpopulation of neurons in the medial prefrontal cortex encodes emotional learning with burst and frequency codes through a dopamine $\mathrm{D}_{4}$ receptor-dependent basolateral amygdala input. J Neurosci 25:6066-6075.

LeDoux JE (2000) Emotion circuits in the brain. Annu Rev Neurosci 23:155-184.

LeDoux JE, Iwata J, Cicchetti P, Reis DJ (1988) Different projections of the central amygdaloid nucleus mediate autonomic and behavioral correlates of conditioned fear. J Neurosci 8:2517-2529.

Liberzon I, Sripada CS (2008) The functional neuroanatomy of PTSD: a critical review. Prog Brain Res 167:151-169.

Likhtik E, Pelletier JG, Paz R, Paré D (2005) Prefrontal control of the amygdala. J Neurosci 25:7429-7437.

Maren S, Quirk GJ (2004) Neuronal signalling of fear memory. Nat Rev Neurosci 5:844-852.

Maren S, Aharonov G, Fanselow MS (1997) Neurotoxic lesions of the dorsal hippocampus and Pavlovian fear conditioning in rats. Behav Brain Res 88:261-274.

Maxwell B, Powell DA, Buchanan SL (1994) Multiple- and single-unit activity in area 32 (prelimbic region) of the medial prefrontal cortex during Pavlovian heart rate conditioning in rabbits. Cereb Cortex 4:230-246.

McDonald AJ (1991) Organization of amygdaloid projections to the prefrontal cortex and associated striatum in the rat. Neuroscience 44:1-14.

Mcdonald AJ, Mascagni F, Guo L (1996) Projections of the medial and lateral prefrontal cortices to the amygdala: a Phaseolus vulgaris leucoagglutinin study in the rat. Neuroscience 71:55-75.

McLaughlin J, Skaggs H, Churchwell J, Powell DA (2002) Medial prefrontal cortex and pavlovian conditioning: trace versus delay conditioning. Behav Neurosci 116:37-47.

Milad MR, Quirk GJ (2002) Neurons in medial prefrontal cortex signal memory for fear extinction. Nature 420:70-74.

Milad MR, Wright CI, Orr SP, Pitman RK, Quirk GJ, Rauch SL (2007a) Recall of fear extinction in humans activates the ventromedial prefrontal cortex and hippocampus in concert. Biol Psychiatry 62:446-454.

Milad MR, Quirk GJ, Pitman RK, Orr SP, Fischl B, Rauch SL (2007b) A role for the human dorsal anterior cingulate cortex in fear expression. Biol Psychiatry 62:1191-1194.

Milad MR, Ellis CB, Gold A, Shin LM, Handwerger K, Lasko N, Orr SP, Pitman RK, Rauch SL (2008) Neuroimaging correlates of impaired extinction memory in PTSD. Soc Neurosci Abstr 34:190.6.

Muigg P, Hetzenauer A, Hauer G, Hauschild M, Gaburro S, Frank E, Landgraf $\mathrm{R}$, Singewald N (2008) Impaired extinction of learned fear in rats selectively bred for high anxiety-evidence of altered neuronal processing in prefrontal-amygdala pathways. Eur J Neurosci 28:2299-2309.

Paré D, Collins DR (2000) Neuronal correlates of fear in the lateral amygdala: multiple extracellular recordings in conscious cats. J Neurosci 20:2701-2710.

Paré D, Quirk GJ, Ledoux JE (2004) New vistas on amygdala networks in conditioned fear. J Neurophysiol 92:1-9.

Phelps EA, Delgado MR, Nearing KI, LeDoux JE (2004) Extinction learning in humans: role of the amygdala and vmPFC. Neuron 43:897-905.

Powell DA, Maxwell B, Penney J (1996) Neuronal activity in the medial prefrontal cortex during pavlovian eyeblink and nictitating membrane conditioning. J Neurosci 16:6296-6306.

Quirk GJ, Mueller D (2008) Neural mechanisms of extinction learning and retrieval. Neuropsychopharmacology 33:56-72.

Quirk GJ, Repa C, LeDoux JE (1995) Fear conditioning enhances shortlatency auditory responses of lateral amygdala neurons: parallel recordings in the freely behaving rat. Neuron 15:1029-1039.

Quirk GJ, Russo GK, Barron JL, Lebron K (2000) The role of ventromedial prefrontal cortex in the recovery of extinguished fear. J Neurosci 20:6225-6231.

Quirk GJ, Garcia R, González-Lima F (2006) Prefrontal mechanisms in extinction of conditioned fear. Biol Psychiatry 60:337-343.

Repa JC, Muller J, Apergis J, Desrochers TM, Zhou Y, LeDoux JE (2001) Two different lateral amygdala cell populations contribute to the initiation and storage of memory. Nat Neurosci 4:724-731.

Resstel LB, Corrêa FM, Guimarães FS (2008) The expression of contextual fear conditioning involves activation of an NMDA receptor nitric oxide pathway in the medial prefrontal cortex. Cereb Cortex 18:2027-2035.

Rodriguez-Romaguera J, Sotres-Bayon F, Mueller D, Quirk GJ (2009) Systemic propranolol acts centrally to reduce conditioned fear in rats without impairing extinction. Biol Psychiatry 65:887-892. 
Room P, Russchen FT, Groenewegen HJ, Lohman AH (1985) Efferent connections of the prelimbic (area 32) and the infralimbic (area 25) cortices: an anterograde tracing study in the cat. J Comp Neurol 242:40-55.

Schienle A, Schäfer A, Hermann A, Rohrmann S, Vaitl D (2007) Symptom provocation and reduction in patients suffering from spider phobia: an fMRI study on exposure therapy. Eur Arch Psychiatry Clin Neurosci 257:486-493.

Schiepek G, Tominschek I, Karch S, Lutz J, Mulert C, Meindl T, Pogarell O (2008) A controlled single case study with repeated fMRI measurements during the treatment of a patient with obsessive-compulsive disorder: testing the nonlinear dynamics approach to psychotherapy. World J Biol Psychiatry 1-11.

Schoenbaum G, Setlow B (2003) Lesions of nucleus accumbens disrupt learning about aversive outcomes. J Neurosci 23:9833-9841.

Shi WX, Zhang XX (2003) Dendritic glutamate-induced bursting in the prefrontal cortex: further characterization and effects of phencyclidine. J Pharmacol Exp Ther 305:680-687.
Shin LM, Rauch SL, Pitman RK (2006) Amygdala, medial prefrontal cortex, and hippocampal function in PTSD. Ann N Y Acad Sci 1071:67-79.

Shin LM, Bush G, Whalen PJ, Handwerger K, Cannistraro PA, Wright CI, Martis B, Macklin ML, Lasko NB, Orr SP, Pitman RK, Rauch SL (2007) Dorsal anterior cingulate function in posttraumatic stress disorder. J Trauma Stress 20:701-712.

Swanson LW (1992) Brain maps: structure of the rat brain. New York: Elsevier.

Thierry AM, Gioanni Y, Dégénétais E, Glowinski J (2000) Hippocampoprefrontal cortex pathway: anatomical and electrophysiological characteristics. Hippocampus 10:411-419.

Vertes RP (2004) Differential projections of the infralimbic and prelimbic cortex in the rat. Synapse 51:32-58.

Vidal-Gonzalez I, Vidal-Gonzalez B, Rauch SL, Quirk GJ (2006) Microstimulation reveals opposing influences of prelimbic and infralimbic cortex on the expression of conditioned fear. Learn Mem 13:728-733. 